\title{
Wheat Straw Pre-treatments using Eco-Friendly Strategies for Enhancing the Tensile Properties of Bio-based Polylactic Acid Composites
}

Mehdi Chougana, Seyed Hamidreza Ghaffar ${ }^{\mathrm{a}}$, Mazen J. Al-Kheetan ${ }^{\mathrm{b}}$, Mantas Gecevicius ${ }^{\mathrm{a}}$,

${ }^{a}$ Department of Civil and Environmental Engineering, Brunel University London, Uxbridge, UB8 3PH, United Kingdom

${ }^{\mathrm{b}}$ Civil and Environmental Engineering Department, Mutah University, Mutah, Karak 61710, Jordan, P.O.BOX 7

*Corresponding Author: Seyed.Ghaffar@brunel.ac.uk

\section{Abstract}

Individual and hybrid pre-treatments, including hot water, steam and microwave were used on wheat straw to mitigate the surface quality deficiencies for an intimate interfacial bond between substrate and Polylactic Acid matrix. Microstructural analysis showed the expansion of cells due to the pretreatments which in turn promotes mechanical entanglement between wheat straw and PLA, thus, improving the tensile properties of bio-based composites. The tensile strength, elastic modulus, and toughness increased by $166 \%, 68 \%$, and $285 \%$, respectively, for pre-treated wheat straw compared to untreated.

\section{Introduction}

The utilisation of straw biomass in bio-based composites is gaining momentum due to their cost efficiency, lightweight, low density and less environmental impact during production (Mati-Baouche et al., 2014; Sahai and Pardeshi, 2019). So far, the most commonly used material for bio-based composites fabrication is wood (Anugwom et al., 2019; Kaboorani, 2017) but, wheat straw as a renewable material has the potential to successfully replace wood in various applications. In general, wheat straw has similar chemical constituents to those of wood (i.e. cellulose, hemicellulose, lignin, and extractives). However, wheat straw has a higher content of hydrophobic waxy cuticle layers and high amount of inorganic silica and extractives (Alemdar and Sain, 2008a; Ghaffar and Fan, 2015a, 2015b, 2014, 2013; Han et al., 2009). The comparatively poor surface properties of wheat straw with hydrophobic components can reduce the interfacial bond quality between the substrate and polymer binder. This has eventually hampered the commercialisation of wheat straw bio-based composites (Ghaffar et al., 2017a, 2017b; Ghaffar and Fan, 2017). Several other lingo-cellulosic biomass, including cereal straw, hemp and jute strands, henequen strands, corn cobs, cotton stalks, kenaf, bamboo and rice husks, sunflower stalks, and Bagasse have been proposed as reinforcements for bio-based composite fabrication (English and Spelter, 1992; Guo et al., 2018; Liu et al., 2017; Melo et al., 2014; Tarrés et al., 2019; Tran et al., 2014; Tribot et al., 2018; Yu et al., 2019). 
For instance, Scaffaro et al. reported that the incorporation of reinforcing agents such as Posidonia Oceanica leaves and Opuntia Ficus Indica in poly-lactic acid (PLA) and Mater $\mathrm{Bi}^{\circledast}$ (MB) polymeric matrices increase the stiffness, while decreasing toughness, elongation at break and tensile strength of bio-based composites (Scaffaro et al., 2020, 2019, 2018).

Several methods have been developed in order to improve the surface compatibility of the natural reinforcements by additive incorporation as well as employing a variety of pre-treatment processes to produce a high-performance bio-based composites. Physical pre-treatment methods, including steam cooking, steam explosion, liquid-plasma, and ozonation (Ghaffar et al., 2017b; Putra et al., 2020), as well as chemical pre-treatments such as mercerization, acetylation, enzymatic, and alkaline pre-treatments (Ghaffar and Fan, 2015a; Hýsek et al., 2018; Hýsková et al., 2020; X. Li et al., 2007), have been shown to be beneficial in terms of (i) modifying the surface of straw with the partial removal of extractives, waxes, and silica which made it more hydrophilic and more compatible with waterbased resins, (ii) expanding the microcellular structure of straw and hence improving the penetration of matrix into cell lumens, leading to intimate bonding quality between substrate and matrices (Elbashiry et al., 2018; Oushabi, 2019). Wang et al. (2018) employed an alkaline pre-treatment using $4 \mathrm{wt} \%$ sodium hydroxide $(\mathrm{NaOH})$ solution for bamboo fibers, which led to an increase in the elongation at break and tensile strength of the polylactide composites filled with alkaline treated fibres by $84 \%$ and 49\%, respectively (Wang et al., 2018). The chemical pre-treatment decreases the hydrophilicity of biomass and increases the fibre surface's roughness, which increases the adhesion between fibres and the surrounding polymeric matrices (Manshor et al., 2014). On the other hand, Santos et al. reported the remarkable effectiveness of hot water pre-treatment of piassava Attalea funifera fibres which increases the cellulose peak intensity and crystallinity index of the fibres(Santos et al., 2018). It should be noticed that chemical pre-treatments are shown to be effective in the destruction and extraction of a certain amount of lignin, hemicellulose, and pectin covering the biomass surface, resulting in better-purified cellulose. However, the low cost-efficiency of the procedure in large scale production and their harmful environmental impacts limits their extensive applications over physical pretreatments (Tian et al., 2018). Additionally, the use of coupling agents has proved to be effective, especially with wood-based plastic composites (Ghaffar et al., 2018). Coupling agents such as Silane (Gurunathan et al., 2015), maleic anhydride (MA) (Mishra et al., 2000), polydopamine (PDA) (Fan et al., 2018), and attapulgite clay (ATP) (Zhu et al., 2019) can modify the surface properties and enhance the bonding/adhesion between cellulosic biomass and polymer matrices. The mechanism is formed through the reaction between hydroxyl groups at one end, and natural fibre surface and another fun ctional group at the other end in order to bond with the polymer matrices (Ghaffar et al., 2018). 
In this study, as a novelty, wheat straw was optimised by selective separation of defects in the context of bio-based composites (i.e. nodes, see Figure 1a). Node has a very different microstructure to that of the internode (Ghaffar and Fan, 2015a). It is much less structurally competent, specifically in tension, furthermore, node's surface chemical functional groups, precisely their higher extractives and hydrophobic wax, inhibit the good interfacial bonding between the substrate and matrix in bio-based composites (Ghaffar et al., 2017a; Ghaffar and Fan, 2015a). Therefore, after the separation of nodes, the internodes of wheat straw were subjected to various hybrid pre-treatments, including hot water followed by steam for two different time durations and microwave pre-treatment. The employed pretreatments are cost-effective and prevent the entry of hazardous and toxic chemical reagents to the environment. Comprehensive materials characterisation were conducted, and bulk property evaluation of bio-based composites was also carried out in order to evaluate the effects of pretreatments on potential tensile strength improvements.

\section{Materials and methodology}

As-received material, wheat straw (Triticum aestivum L.), was obtained from a residential farm, Middlesex, United Kingdom, harvested in late summer of 2019. The material was baled and dried directly on-site. The thermoplastic polylactic acid (PLA), supplied by Tecnaro GmbH, Ilsfeld, Germany, was used as the matrix binder in this study. All materials were stored in ambient room temperature to keep air-dryness.

\subsection{Wheat straw preparation for pre-treatment}

Prior to the pre-treatment stage, as-received straw was bailed out and prepared for the cleaning stage. As previously reported (Harper and Lynch, 1981), straw is comprised of internodes (57 $\pm 10 \%)$, nodes (10 $\pm 2 \%)$, leaves $(18 \pm 3 \%)$, chaffs $(9 \pm 4 \%)$ and rachis $(6 \pm 2 \%)$ by mass, which leads to exhibit an inconsistency in chemical distribution. The wheat straw stems were cut above and below the nodes for the internode separation, and the internode parts were extracted by hand. After the cleaning process, all samples were dried in the oven at $100 \pm 5{ }^{\circ} \mathrm{C}$ for 24 hours. In total, three hazardoussubstance-free pre-treatments with straw to water ratio of 1:100 (by weight) and starting water temperature of $100{ }^{\circ} \mathrm{C}$ were conducted in this study (see Figure $\mathbf{1} \mathbf{b}$-e).

\section{Figure 1}

\subsubsection{H+S pre-treatment}

$\mathrm{H}+\mathrm{S}$ pre-treatment contains two consecutive stages (i.e. hot water and steam stages). In the first stage, the straw was introduced into a pressure cooker for 60 minutes, which was tightly sealed to maintain a constant pressure of approximately $0.1 \mathrm{MPa}$. Hot water $(\mathrm{H})$ stage was then followed by steam treatment stage $(S)$ by removing the straw from hot water and placing them into mesh basket 
instantly, which was positioned directly above boiling water inside the pressure cooker. In this stage, the steam was allowed to pass through the wheat straw for another 30 minutes.

\subsection{H+S pre-treatment}

The $0.5 \mathrm{H}+\mathrm{S}$ pre-treatment was conducted exactly as the $\mathrm{H}+\mathrm{S}$ pre-treatment procedure, except the hot water stage, was shortened to 30 minutes (i.e. $0.5 \mathrm{H}$ ).

\subsubsection{H+M pre-treatment}

The term $\mathrm{H}$ refers to the first pre-treatment stage (i.e. Hot water) in which the straw was boiled in the pressure cooker for 60 minutes. While the term $\mathrm{M}$ refers to microwave pre-treatment in which the straws were spread evenly on the tray and placed into standard microwave at 900 watts for 15 minutes.

\subsection{Experimental plan}

Figure 2 illustrates the testing programme followed for this study.

\section{Figure 2}

\subsection{Bio-based composites sample preparation}

Before the composite production, all the untreated and pre-treated straws were cut into 5-15 mm pieces by employing Retsch SM 100 cutting mill for bio-based composites. The composites in this study were fabricated using PLA and internode part extracted from wheat straw with a ratio of 1:1 by weight. For each sample, the chopped straw and polymer pellets were mixed to achieve the uniform arrangement of material (see Figure 3a). The mixture was placed into the steel mould of size $100 \mathrm{~mm}$ $\times 100 \mathrm{~mm} \times 20 \mathrm{~mm}$ (see Figure 3b). The mould was then placed in the hot-air oven for 15 minutes at $200 \pm 10^{\circ} \mathrm{C}$ to facilitate the PLA melting process. After the pre-heating step, the mould with softened PLA and straws was hot-pressed for 20 minutes at $180{ }^{\circ} \mathrm{C}$ under the pressure of $10 \mathrm{MPa}$. After removing the mould from the hot-press, a mass of $15 \mathrm{~kg}$ was placed on top of the samples to prevent the expansion phenomenon. Furthermore, the manufactured composite was left for 30 minutes to cool down to reach the ambient temperature. Finally, the finished products were cut precisely into $20 \mathrm{~mm}$ wide strips to form tensile test samples. Four stripes for tensile strength evaluation were cut out from one strawboard (see Figure 3c).

\section{Figure 3}

\subsection{Characterisations and testing}

\subsubsection{Microstructure}

The morphology of wheat straw was assessed by scanning electron microscopy (SEM). Cross-section of the untreated and pre-treated internodes were studied using Supra 35VP, Carl Zeiss, Germany. To obtain a reliable statement about the microstructure and the changes induced as a result of pretreatments, at least ten samples with the size of $10 \mathrm{~mm}^{3}$ were analysed. ImageJ software was 
employed in order to quantitatively evaluate the thickness of the epidermis layer and area percentage of the parenchyma.

\subsubsection{Crystallinity}

The powder X-ray diffraction was performed to investigate the changes in the crystalline structure of four powdered samples of untreated, $\mathrm{H}+\mathrm{S}, 0.5 \mathrm{H}+\mathrm{S}$, and $\mathrm{H}+\mathrm{M}$ employing a D8 advanced Bruker AXS diffractometer, $\mathrm{Cu}-\mathrm{K} \alpha$ radiation, wavelength of $1.542 \AA, 2 \theta$ of $20-40^{\circ}$ at $40 \mathrm{kV}$ and $40 \mathrm{~mA}$.

Based on the XRD results, the crystallinity index $(\mathrm{Cl})$ was calculated by an empirical method suggested by Segal et al. (1959) (Eq.1) (Segal et al., 1959). However, the Cl term is reliable only in the interest of comparison as it specifies the order of crystallinity rather than the crystallinity of crystalline regions.

$$
C I(\%)=\frac{I_{002}-I_{\text {amorph }}}{\mathrm{I}_{002}} \times 100
$$

In this equation, the $\mathrm{l}_{002}$ is the maximum intensity of the $\left(\begin{array}{lll}0 & 0\end{array}\right)$ lattice diffraction and represents both crystalline and amorphous region of the materials (i.e. $2 \theta$ between $20^{\circ}$ and $24^{\circ}$ ), and lamorph represents the amorphous region of the material (i.e. $2 \theta$ between $17^{\circ}$ and $20^{\circ}$ ).

\subsubsection{Surface chemical functional group distribution}

Attenuated total reflectance-Fourier transform infrared spectroscopy (FTIR-ATR) was used by employing a PerkinElmer Spectrum one Spectrometer. The samples, including the inner and outer surface of randomly selected untreated and pre-treated straw internodes, were mounted on an (ATR) equipped with a $3 x$ bounce diamond crystal with an incident angle of $45^{\circ}$. The instrument produced 20 scans with a resolution of $4 \mathrm{~cm}^{-1}$ at a wavenumber ranged between $4000 \mathrm{~cm}^{-1}$ and $600 \mathrm{~cm}^{-1}$. A batch of three samples have been tested for each composition and the average results are reported.

\subsubsection{Water contact angle}

The water contact angle test was performed to assess the wettability of wheat straw outer surface using the First Ten Angstroms FTA 1000 Analyser System. The angle between the water droplet surface and the sample surface was measured every $100 \mathrm{~s}$ for a total of $500 \mathrm{~s}$. Ten different specimens were tested for each pre-treatment. The wettability of each sample was investigated by measuring the initial contact angle $\left(\theta_{\mathrm{i}}\right)$, and the equilibrium contact angle $\left(\theta_{\mathrm{e}}\right)$. The penetration and spreading constant (K) values (Shi and Gardner, 2001), were calculated by employing the wetting model (i.e. Eq. 2) in OriginPro software. In principle, $K$ value determines the liquid penetration proficiency within the surface of wheat straw.

$$
\theta=\frac{\theta_{i} \theta_{e}}{\theta_{i}+\left(\theta_{e}-\theta_{i}\right) \exp \left[K\left(\frac{\theta_{e}}{\theta_{e}-\theta_{i}}\right) t\right]}
$$

\subsubsection{Thermogravimetric analysis}

The thermogravimetric analysis of straw was performed to compare their degradation characteristics. The thermal stability of each sample was obtained employing an SDT Q600 V8.3 Build 101 (TA 
instrument). The samples of about $3-4 \mathrm{mg}$ were heated from 20 to $650{ }^{\circ} \mathrm{C}$ at a rate of $10^{\circ} \mathrm{C} / \mathrm{min}$ in a continuous flow of nitrogen (i.e. nitrogen atmosphere) to avoid unwanted oxidation.

\subsection{Mechanical properties}

The tensile strength performance of the samples was assessed according to the ASTM D3039/D3039M using Instron 5969 universal testing machine equipped with wedge action tensile grips. The tensile tests were carried out on the strawboard strips of size $100 \mathrm{~mm} \times 20 \mathrm{~mm} \times 20 \mathrm{~mm}$. Specimens were inserted $40 \mathrm{~mm}$ into the grips to create a $20 \mathrm{~mm}$ gauge length. A total of 20 samples were tested, and relevant data collected. Modulus of elasticity, elongation at break, and tensile toughness were also calculated from the stress-strain curve by measuring the slope at the elastic region, percentage of maximum extension vs. initial size of the sample at the point of rupture, and integrating the area under the stress-strain curve, respectively, employing the tangent and integration gadgets in OriginPro software.

\subsection{Physical properties}

181 The dimension stability of the strawboards, including thickness swelling (TS) and water absorption 182 (WA) tests, was evaluated in accordance with the BS 5669-1:1989. Prior to the tests, the thickness 183 and weight of each specimen were precisely measured by means of digital equipment. Six samples 184 for each specimen type were tested.

\section{3. Results and Discussion}

\subsection{Microstructural changes due to pre-treatments}

In order to analyse and compare the microstructure of untreated and pre-treated wheat straw, SEM was used to investigate the cross-section of the wheat straw internode. Results revealed that all the pre-treatments, induced the desired changes in the microstructure of wheat straw internode, precisely, reducing the thickness of epidermis as a result of hot water $(\mathrm{H})$ stage and expansion of parenchyma, which could potentially facilitate the deeper and more efficient penetration of polymer matrix in liquid form. The aforementioned desired changes lead to better quality bonding and subsequently, higher performing bio-based composites. Figure 4 a-d shows that the pre-treatment reduced the thickness of the epidermis layer from $103.6 \mu \mathrm{m}$ for the untreated straw to $54.8 \mu \mathrm{m}, 65.7$ $\mu \mathrm{m}$, and $70.9 \mu \mathrm{m}$ for $\mathrm{H}+\mathrm{S}, 0.5 \mathrm{H}+\mathrm{S}$, and $\mathrm{H}+\mathrm{M}$ pre-treated samples, respectively. Since the epidermis layer contains hydrophobic silicone and waxes components, reducing the size of this layer could be beneficial as it means the polymer matrix will bond better with the wheat straw due to the reduced hydrophobic contact area. In addition, the area percentage of the parenchyma for each sample was calculated by employing the ImageJ software. The results revealed that $\mathrm{H}+\mathrm{S}$ and $0.5 \mathrm{H}+\mathrm{S}$ pretreatments, i.e. Figure $\mathbf{4} \mathbf{b}$ and $\mathbf{c}$, show a noticeable expansion of parenchyma, approximately $12 \%$ for $\mathrm{H}+\mathrm{S}$ and $10 \%$ for $0.5 \mathrm{H}+\mathrm{S}$ compared to untreated wheat straw samples, therefore, becoming broader 
and more in-depth. Moreover, the thickness of the cell walls, which can affect the mechanical interlocking with polymeric matrices, slightly decreased. It is evident that the steaming $(\mathrm{S})$ stage of $\mathrm{H}$ $+\mathrm{S}$ and $0.5 \mathrm{H}+\mathrm{S}$ pre-treatments has led to the deepening of wheat straw layers, which resulted in the expansion of parenchyma. The same modifications can be observed in $\mathrm{H}+\mathrm{M}$ pre-treatment (Figure 4 d) without the steaming stage, i.e. 9\% expansion compared to untreated sample. This reflects the microwave (M) stage of the pre-treatment acting as a pressure steaming. Kashaninejad et al. (2010) also reported that the microwave pre-treatment increased the internal surface area of the wheat straw structure, which was evidenced by a decrease in bulk and particle density as well as an increase in the overall particle size of wheat straw (Kashaninejad et al., 2010).

\section{Figure 4}

\subsection{Physicochemical changes due to pre-treatments}

The FTIR-ATR spectroscopy was employed to characterise the chemical distribution of the inner and outer surface of straw internodes. The node parts of the straw stem are separated and taken out from the experiments following the authors' previous work, which indicated that nodes possess higher levels of hydrophobic wax and silica on their surface compared to the internodes (Ghaffar et al., 2017a; Ghaffar and Fan, 2015b). This was proven to be an inhibiting factor for interfacial bonding quality in the context of the composite (Ghaffar et al., 2017a). The bands at $790 \mathrm{~cm}^{-1}$ and $985 \mathrm{~cm}^{-1}$ are referred to the silicon carbide $(\mathrm{Si}-\mathrm{C}$ ) and silicon oxide $(\mathrm{Si}-\mathrm{O})$ stretching vibration bonds, respectively (Frost and Mendelovici, 2006), which presented only in the spectrums obtained for the outer surface of wheat straw internode (see Figure $\mathbf{5} \mathbf{b}$ ). This suggested that silicon components mainly appeared on the outer surface. Pre-treatments reduced silicon components, particularly in $\mathrm{H}+\mathrm{S}$ pre-treatment, there is a drastic reduction in the silica bands on the outer surface.

\section{Figure 5}

In order to fully validate the silicon components' reduction phenomenon, the thermal degradation of both untreated and $\mathrm{H}+\mathrm{S}$ pre-treated wheat straw internode has been assessed using TGA analysis, shown in Figure 6. In the TGA curves, there are three distinct degradation stages. The first stage (i.e. between $100-150^{\circ} \mathrm{C}$ ) relates to initial weight loss generated the moisture evaporation, and it is highly associated with the initial moisture of samples. The second stage (i.e. between $250-350{ }^{\circ} \mathrm{C}$ ) refers to the severe weight loss formed by cellulose and hemicellulose degradation. Finally, the third stage is representing the decomposition of non-cellulosic components (i.e. lignin) (Ghaffar and Fan, 2015a). The enhanced thermal stability of straw and the high onset of degradation temperature are directly linked together, meaning that the higher degradation onset signifies the better thermal stability of straw (Ghaffar and Fan, 2015a; Zandi et al., 2019). The onset of degradation temperature for H+S pretreated straw (i.e. $315^{\circ} \mathrm{C}$ ) is relatively higher than that of untreated straw (i.e. $296{ }^{\circ} \mathrm{C}$ ), which is due 
to the extraction of hemicelluloses and waxy substances generated by the $\mathrm{H}+\mathrm{S}$ pre-treatment. Moreover, the higher crystalline structure of straw after $\mathrm{H}+\mathrm{S}$ pre-treatment needs more temperature for degradation concerning the untreated straw. This was confirmed by the intensity reductions at bands $1735 \mathrm{~cm}-1$ for hemicelluloses extraction as well as $2920 \mathrm{~cm}-1$ and $2850 \mathrm{~cm}-1$ for the removal of waxy substances (Saari et al., 2014). Moreover, the higher crystalline structure of straw after $\mathrm{H}+\mathrm{S}$ pre-treatment needs more temperature for degradation concerning the untreated straw (Alemdar and Sain, 2008a).

On the other hand, the high volume of ash and silica on the outer surface of straw, negatively affects the incorporation of these materials in bio-based composites applications. Qin et al. (2010) reported that the Residual weight at $600{ }^{\circ} \mathrm{C}$ refers to the remained ash content (Qin et al., 2011). The results revealed that the ash content after $\mathrm{H}+\mathrm{S}$ pre-treatments is relatively lower (i.e. $4.5 \%$ ) compared to the untreated sample (i.e. 11\%). The reduction in the ash and silica content of the straw improves the interfacial bonding between the straw and polymer-matrices, which eventually leads to an increase in the feasibility of using these materials in bio-based composites (Kaewtatip and Tanrattanakul, 2008).

Figure 6

Bands at $1595 \mathrm{~cm}^{-1}$ and $1510 \mathrm{~cm}^{-1}$ correspond to aromatic ring stretch of lignin, which is particularly enhanced in the inner surface of pre-treated straw samples (Yang et al., 2020). The sharpest peaks of lignin bands can be observed as a result of $\mathrm{H}+\mathrm{M}$ and $0.5 \mathrm{H}+\mathrm{S}$ pre-treatments, which suggest the release and re-deposition of lignin on the surface of the straw during the pre-treatment process. (Kaparaju and Felby, 2010; Kristensen et al., 2008; J. Li et al., 2007). The carboxyl groups in the acids and esters of acetic, $p$-coumeric, ferulic, and uronic acids, was appeared at band $1735 \mathrm{~cm}^{-1}$, which represents the principal constituents of extractives and hemicellulose (Alemdar and Sain, 2008b). The intensity of this band was reduced by $\mathrm{H}+\mathrm{S}$ and $0.5 \mathrm{H}+\mathrm{S}$ pre-treatments compared to $\mathrm{H}+\mathrm{M}$ pretreatment, indicating higher removal of hemicellulose. Moreover, the absence of a $1735 \mathrm{~cm}^{-1}$ peak in the inner surface of wheat straw indicates that hemicellulose fractions are relatively lower in the inner surface of the wheat straw. Sharp peaks at $2920 \mathrm{~cm}^{-1}$ and $2850 \mathrm{~cm}^{-1}$ both in outer and inner surfaces represent asymmetric and symmetric $\mathrm{CH}_{2}$ stretching bands, which correspond to the aliphatic fractions of waxes (Merk et al., 1997). Results show that the outer surface of the internode consists of higher amounts of wax and inorganic substances concerning the inner surface (see Figure $\mathbf{5} \mathbf{a}-\mathbf{b}$ ). The pre-treatments showed a positive effect in the reduction of inorganic substances and waxes. The highest reduction in the intensity of this band occurred for $\mathrm{H}+\mathrm{S}$ pre-treatment, which shows a notable decrease in the amount of hydrophobic wax. The outer surface of the straw internode contains plenty of cell elements, including parenchyma cells, fibres, vessel elements, and epidermis (Ghaffar et al., 2017a). Among the aforementioned cell elements, the outmost surface cell (i.e. epidermis) comprises 
dense and thick-walled cells covered with cutin cuticle wax. Figure $\mathbf{7}$ demonstrates the water contact angle results of untreated (UN) and $\mathrm{H}+\mathrm{S}$ pre-treated straw samples. The results show the significant impact of pre-treatment on the wettability of straw in which the $\theta_{\mathrm{i}}$ and $\theta_{\mathrm{e}}$ were decreased from $88.73^{\circ}$ and $69.79^{\circ}$ for the untreated sample to $64.06^{\circ}$ and $34.59^{\circ}$ for $\mathrm{H}+\mathrm{S}$ pre-treated samples, respectively. As shown in Figure 7, the K value has been increased from $1.56 \times 10^{-4}$ for the untreated sample to 10.5 $\times 10^{-4}$ for $\mathrm{H}+\mathrm{S}$ pre-treatment. This shows that the $\mathrm{H}+\mathrm{S}$ pre-treatment has led to hydrophilic surface behaviour. The improvements obtained in the wettability of straw could be associated with two phenomena. First, the $\mathrm{H}+\mathrm{S}$ pre-treatment causes partial removal of some substances (i.e. lignin, pectin, waxy substances, and natural oils), which cover the outer surfaces of straw stem (Mwaikambo and Ansell, 2002). Second, the surface porosity improves as a result of extractives removal during hot water $(\mathrm{H})$ stage followed by expansion of pores during the steaming (S) stage, this, in turn, increases the surface pores dimensions, leading to more hydrophilic surface behaviour. According to several studies (Kaparaju and Felby, 2010; Mosier et al., 2005), the boiling stage can result in partial hemicellulose extraction and changes to the lignin structure in the straw biomass. In general, the reduction in the hemicellulose and cellulose content could be resulting in an increase in porosity volume (Grethlein, H.E., 1985; Kaparaju and Felby, 2010; Zheng et al., 2018). The wettability improvements generated by the $\mathrm{H}+\mathrm{S}$ pre-treatment improves the surface matrices adhesion. Sun et al. (2003) also reported a positive effect of hot water (i.e. approximately $80-90 \mathrm{C}$ for $30 \mathrm{~min}$ ) pretreatment of wheat straw, which released the original lipophilic extractives by $41-53 \%$ (Sun et al., 2003).

\section{Figure 7}

\subsection{Crystallinity index changes due to pre-treatments}

Powder X-ray diffraction analysis of the wheat straw internodes was collected before and after pretreatments. As can be seen in Figure 8, the highest intensity was observed at $2 \theta=21.69-21.85^{\circ}$, which represents the 002 lattices (Ghaffar and Fan, 2015a; Kaushik et al., 2010). Moreover, the secondary peak at $2 \theta=18^{\circ}$ was also observed, which confirms the presence of cellulose with the form of cellulose I crystal. The results also confirm that the peak intensities were slightly increased due to the pretreatments. Table 1 illustrates the crystallinity index of untreated and pre-treated straw samples. The highest crystallinity index was obtained for hot water followed by microwave $(H+M)$ pre-treatment, i.e. $52 \%$, compared to the untreated straws, i.e. $48 \%$. The crystallinity index increase generated by the pre-treatments can be attributed to the extraction of fundamentally amorphous polymers within the constituents of wheat straw, i.e. lignin and hemicellulose (Alemdar and Sain, 2008a). Similar results have been reported on bamboo fibres by Fatriasari et al. (2016). Their results indicated that the microwave power deteriorate the lignin network along with the removal of hemicellulose within the 
substrate structure by molecular vibration. Moreover, the microwave irradiation increases the total crystalline cellulose contents of the surface of the natural fibres, hence increases the crystallinity index percentage (Fatriasari et al., 2016).

\section{Figure 8}

Table 1 - Crystallinity index of wheat straw internode samples with and without pre-treatments.

\begin{tabular}{lcc}
\hline Sample & $\begin{array}{c}\text { Crystallinity } \\
\text { index (\%) }\end{array}$ & $\begin{array}{c}\text { Crystallinity index } \\
\text { change (\%) }\end{array}$ \\
\hline $\mathrm{UN}$ & $48( \pm 0.3)^{*}$ & N/A \\
$\mathrm{H}+\mathrm{S}$ & $50( \pm 0.1)$ & 5.0 \\
$0.5 \mathrm{H}+\mathrm{S}$ & $50( \pm 0.5)$ & 4.0 \\
$\mathrm{H}+\mathrm{M}$ & $52( \pm 0.1)$ & 9.0 \\
\hline
\end{tabular}

\subsection{Tensile properties improvements of wheat straw bio-based composites}

The tensile strength properties assessments, including elastic modulus and tensile toughness, and elongation at break have been carried out to investigate the efficacy of pre-treatments on the mechanical proficiency of bio-based composites. The coefficient of variation (CoV \%) for all the compositions was calculated, which varied from $1 \%$ to $7.5 \%$, to define the statistical significance.

Prior to tensile testing, the average density of bio-based composites $s$ was calculated, as shown in Figure 9. The results revealed that the presence of pre-treated straw in bio-based composites induces a negligible reduction in density compared to that of bio-based composites with untreated straw. The term high-density fibreboard composites refers to the composites with the density higher than $0.8 \mathrm{~g} / \mathrm{cm}^{3}$ (Guo et al., 2020; Mamiński et al., 2018). In this study, the density values of all the biobased composites have been varied between $0.92 \mathrm{~g} / \mathrm{cm}^{3}$ and $0.96 \mathrm{~g} / \mathrm{cm}^{3}$, which indicates the highdensity characteristic of the manufactured bio-based composites.

All the bio-based composites with pre-treated straws showed an increase in strength with respect to the untreated sample (see Figure 9a). The tensile strength increased from 3.75MPa for untreated wheat straw bio-based composites samples to $10 \mathrm{MPa}, 6.6 \mathrm{MPa}$, and $7.9 \mathrm{MPa}$ for $\mathrm{H}+\mathrm{S}, 0.5 \mathrm{H}+\mathrm{S}$, and $\mathrm{H}+\mathrm{M}$ bio-based composites samples, respectively. Furthermore, elastic modulus, tensile toughness, and elongation at break increased for bio-based composites with the pre-treated straws, see Figure 9b. The maximum enhancement compared to untreated straw bio-based composites was observed in $\mathrm{H}+\mathrm{S}$ samples with $68 \%, 285 \%$, and $18 \%$ elastic modulus, tensile toughness, and elongation at break respectively. The remarkable increase in the mechanical performance of pre-treated over untreated bio-based composites could be attributed to several factors. First, the wetting property improvements 
leading to better interfacial bonding between polymer matrices and straw (Rakesh Kumar1, Sangeeta Obrai1, 2011). Second, the cell walls expansion during the steaming stage (S), which allows more polymer to penetrate inside the swollen straw cells and hence increase the bonding. Third, increased crystallinity index, as observed in the X-ray diffraction spectroscopy, indicating the strength improvement of pre-treated samples due to the presence of more stable cellulose chains in their structure (Xiao et al., 2014). Apart from better surface functionality and interaction with PLA, the author's previous studies showed that the tensile strength of $\mathrm{H}+\mathrm{S}$ pre-treated individual strands significantly increased by $35 \%$, reaching $88.9 \mathrm{MPa}$ compared to the untreated strands (i.e. $66 \mathrm{MPa}$ ) (Ghaffar et al., 2017a). All of the points mentioned above explain the improved tensile performance of pre-treated straw bio-based composites compared to the untreated counterparts.

\section{Figure 9}

\subsection{Dimensional stability of pre-treated and untreated wheat straw bio-based composites}

The dimensional stability of manufactured bio-based composites was assessed by employing water absorption (WA), and thickness swelling (TS) tests at 2 and 24 hours. Both WA and TS of all bio-based composites, with and without pre-treated straws increased by time (see Figure $\mathbf{1 0} \mathbf{a}-\mathbf{b}$ ). The WA results indicated that, at 2 hours of immersion, the water intake was increased from 10\% (CoV 3.6\%) for untreated straw bio-based composites to 14\% (CoV 2.1\%), 14\% (CoV 5.2\%) and 13\% (CoV 4.2\%) for $\mathrm{H}+\mathrm{S}, 0.5 \mathrm{H}+\mathrm{S}$, and $\mathrm{H}+\mathrm{M}$, respectively. A comparable trend has been observed for the samples after 24 hours of immersion in water (Figure 10 a). The same effect was observed for TS of bio-based composites, increasing from 3\% ( $\operatorname{CoV} 6.5 \%)$ and $7 \%(\operatorname{CoV} 6.5 \%)$ for untreated straw bio-based composites to $6 \%(\operatorname{CoV} 3.5 \%)$ and $8 \%(\operatorname{CoV} 2.5 \%)$ for $\mathrm{H}+\mathrm{S}$ counterparts at $2 \mathrm{~h}$ and $24 \mathrm{~h}$, respectively (Figure $10 \mathrm{~b}$ ). The bio-based composites with $\mathrm{H}+\mathrm{S}$ pre-treated straws exhibited maximum water absorption at both $2 \mathrm{~h}$ and $24 \mathrm{~h}$. This could be attributed to a decrease in the hydrophobicity of straw strands after pre-treatments, due to diminished levels of wax and silica content (Kalagar, M., Bazyar, B., Khademieslam, H., Ghasmi, and Hemmasi, 2015). Generally, water absorption of commercial boards is approximately 51\% (Jabeen et al., 2014), and maximum thickness swelling after 24 hours immersion time is 15\%, according to BS EN 312:2010 standard. Moreover, as reported by Zheng et al. (2018), the pre-treatments increased the porosity of straw biomass surface structure by partial degradation of hemicellulose and lignin (Wu et al., 2017; Zheng et al., 2018), which allowed the water molecules to penetrate the bio-based composites. This resulted in high water absorption, which subsequently led to increased thickness swelling. The results are aligned with the results reported by Melo et al. (2014), which showed remarkable loss of dimensional stability in rice husk and bamboo particles by $60 \%$ in terms of both WA and TC after $2 \mathrm{~h}$ and $24 \mathrm{~h}$ of immersion (Melo et al., 2014). It has 
been reported that the chemical pre-treatments reduce water absorption (Mishra and Sain, 2009) as a result of the reaction of acetyl groups with hydroxyl groups (Sahai and Pardeshi, 2019).

Figure 10

\section{Conclusions}

The main objective of this study was to develop a wheat straw bio-based composites, using optimised wheat straw particles as reinforcement and PLA as polymer matrix. Several characterisation methods have been carried out, and eventually, mechanical and physical properties of manufactured bio-based composites reinforced with pre-treated and untreated wheat straw were assessed. The main concluding remarks have been drawn out in the following points:

(i) Microstructure changes were observed in all the pre-treated wheat straw, where the pre-

It can be concluded that $\mathrm{H}+\mathrm{S}$ pre-treatment exhibited the maximum enhancement in mechanical properties of wheat straw polylactic acid (PLA) bio-based composites. However, the enhanced surface properties of wheat straw generated by the aforementioned pre-treatment drastically decreased the dimensional stability of final products, there are possible strategies to overcome this shortcoming which will be reported in future study.

\section{Acknowledgements}

392 This work was funded as part of the HPCSB project, which has received funding from the Engineering and Physical Sciences Research Council with the following reference: EP/S026487/1. 
Alemdar, A., Sain, M., 2008a. Biocomposites from wheat straw nanofibers: Morphology, thermal and mechanical properties. Compos. Sci. Technol. 68, 557-565. https://doi.org/10.1016/j.compscitech.2007.05.044

Alemdar, A., Sain, M., 2008b. Isolation and characterization of nanofibers from agricultural residues Wheat straw and soy hulls. Bioresour. Technol. 99, 1664-1671. https://doi.org/10.1016/j.biortech.2007.04.029

Anugwom, I., Lahtela, V., Kallioinen, M., Kärki, T., 2019. Lignin as a functional additive in a biocomposite: Influence on mechanical properties of polylactic acid composites. Ind. Crops Prod. 140. https://doi.org/10.1016/j.indcrop.2019.111704

Elbashiry, E.M.A., Chen, J., Tuo, W., Ren, Y., Guo, Z., 2018. Review of the pretreatment methods for wheat straw building materials. J. Reinf. Plast. Compos. 37, 35-48. https://doi.org/10.1177/0731684417730442

English, B.E., Spelter, H., 1992. Proceedings of the 26th International Particleboard/Composite Materials Symposium. Proc. Washingt. State Univ. Int. Part. Mater. Ser. Symp. 133-152.

Fan, Q., Han, G., Cheng, W., Tian, H., Wang, D., Xuan, L., 2018. Effect of intercalation structure of organo-modified montmorillonite/polylactic acid on wheat straw fiber/polylactic acid composites. Polymers (Basel). 10, 1-14. https://doi.org/10.3390/polym10080896

Fatriasari, W., Syafii, W., Wistara, N., Syamsu, K., Prasetya, B., 2016. Lignin and cellulose changes of betung bamboo (Dendrocalamus asper) pretreated microwave heating. Int. J. Adv. Sci. Eng. Inf. Technol. 6, 186-195. https://doi.org/10.18517/ijaseit.6.2.688

Frost, R.L., Mendelovici, E., 2006. Modification of fibrous silicates surfaces with organic derivatives: An infrared spectroscopic study. J. Colloid Interface Sci. 294, 47-52. https://doi.org/10.1016/j.jcis.2005.07.014

Ghaffar, S.H., Fan, M., 2017. An aggregated understanding of physicochemical properties and surface functionalities of wheat straw node and internode. Ind. Crops Prod. 95, 207-215. https://doi.org/10.1016/j.indcrop.2016.10.045

Ghaffar, S.H., Fan, M., 2015a. Differential behaviour of nodes and internodes of wheat straw with various pre-treatments. Biomass and Bioenergy 83, 373-382. https://doi.org/10.1016/j.biombioe.2015.10.020

Ghaffar, S.H., Fan, M., 2015b. Revealing the morphology and chemical distribution of nodes in wheat straw. Biomass and Bioenergy 77, 123-134. https://doi.org/10.1016/j.biombioe.2015.03.032 
Ghaffar, S.H., Fan, M., 2014. Lignin in straw and its applications as an adhesive. Int. J. Adhes. Adhes. 48, 92-101. https://doi.org/10.1016/j.ijadhadh.2013.09.001

Ghaffar, S.H., Fan, M., 2013. Structural analysis for lignin characteristics in biomass straw. Biomass and Bioenergy 57, 264-279. https://doi.org/10.1016/j.biombioe.2013.07.015

Ghaffar, S.H., Fan, M., McVicar, B., 2017a. Interfacial properties with bonding and failure mechanisms of wheat straw node and internode. Compos. Part A Appl. Sci. Manuf. 99, 102112. https://doi.org/10.1016/j.compositesa.2017.04.005

Ghaffar, S.H., Fan, M., Zhou, Y., Abo Madyan, O., 2017b. Detailed Analysis of Wheat Straw Node and Internode for Their Prospective Efficient Utilization. J. Agric. Food Chem. 65, 9069-9077. https://doi.org/10.1021/acs.jafc.7b03304

Ghaffar, S.H., Madyan, O.A., Fan, M., Corker, J., 2018. The Influence of Additives on the Interfacial Bonding Mechanisms Between Natural Fibre and Biopolymer Composites. Macromol. Res. 26, 851-863. https://doi.org/10.1007/s13233-018-6119-8

Grethlein, H.E., 1985. The effect of pore size distribution on the rate of enzymatic hydrolysis of cellulosic substrates. Bio/Technology 3, 155-160.

Guo, G., Xiang, A., Tian, H., 2018. Thermal and Mechanical Properties of Eco-friendly Poly(Vinyl Alcohol) Films with Surface Treated Bagasse Fibers. J. Polym. Environ. 26, 3949-3956. https://doi.org/10.1007/s10924-018-1270-z

Guo, X.L., Deng, M.S., Wang, J.X., Zhu, Z.L., 2020. Effects of geometric angle and cutting speed on cutting forces and tool wear of ceramic cutting tools during peripheral up-milling of highdensity fiberboard. Materwiss. Werksttech. 51, 461-468. https://doi.org/10.1002/mawe.201900054

Gurunathan, T., Mohanty, S., Nayak, S.K., 2015. A review of the recent developments in biocomposites based on natural fibres and their application perspectives. Compos. Part A Appl. Sci. Manuf. 77, 1-25. https://doi.org/10.1016/j.compositesa.2015.06.007

Han, G., Cheng, W., Deng, J., Dai, C., Zhang, S., Wu, Q., 2009. Effect of pressurized steam treatment on selected properties of wheat straws. Ind. Crops Prod. 30, 48-53. https://doi.org/10.1016/j.indcrop.2009.01.004

Harper, S.H.T., Lynch, J.M., 1981. The chemical components and decomposition of wheat straw leaves, internodes and nodes. J. Sci. Food Agric. 32, 1057-1062. https://doi.org/10.1002/jsfa.2740321103 
Hýsek, Š., Podlena, M., Bartsch, H., Wenderdel, C., Böhm, M., 2018. Effect of wheat husk surface pretreatment on the properties of husk-based composite materials. Ind. Crops Prod. 125, 105113. https://doi.org/https://doi.org/10.1016/j.indcrop.2018.08.035

Hýsková, P., Hýsek, Š., Schönfelder, O., Šedivka, P., Lexa, M., Jarský, V., 2020. Utilization of agricultural rests: Straw-based composite panels made from enzymatic modified wheat and rapeseed straw. Ind. Crops Prod. 144. https://doi.org/10.1016/j.indcrop.2019.112067

Jabeen, S., Naveed, S., Yousaf, S., Ramzan, N., 2014. Effect of wheat straw pretreatments and glue formulations on particle board properties. J. Chem. Soc. Pakistan 36, 50-55.

Kaboorani, A., 2017. Characterizing water sorption and diffusion properties of wood/plastic composites as a function of formulation design. Constr. Build. Mater. 136, 164-172. https://doi.org/10.1016/j.conbuildmat.2016.12.120

Kaewtatip, K., Tanrattanakul, V., 2008. Preparation of cassava starch grafted with polystyrene by suspension polymerization. Carbohydr. Polym. 73, 647-655. https://doi.org/10.1016/j.carbpol.2008.01.006

Kalagar, M., Bazyar, B., Khademieslam, H., Ghasmi, and Hemmasi, A., 2015. Physical and tensile properties of chemically modified wheat straw/poly lactic acid composites. Int. J. Biosci. 6, 8590.

Kaparaju, P., Felby, C., 2010. Characterization of lignin during oxidative and hydrothermal pretreatment processes of wheat straw and corn stover. Bioresour. Technol. 101, 3175-3181. https://doi.org/10.1016/j.biortech.2009.12.008

Kashaninejad, M., Kashaninejad, B., Tabil, L.G., 2010. Effect of microwave pretreatment on densification of wheat straw, in: American Society of Agricultural and Biological Engineers Annual International Meeting 2010, ASABE 2010. pp. 3139-3151. https://doi.org/10.13031/2013.29792

Kaushik, A., Singh, M., Verma, G., 2010. Green nanocomposites based on thermoplastic starch and steam exploded cellulose nanofibrils from wheat straw. Carbohydr. Polym. 82, 337-345. https://doi.org/10.1016/j.carbpol.2010.04.063

Kristensen, J.B., Thygesen, L.G., Felby, C., Jørgensen, H., Elder, T., 2008. Cell-wall structural changes in wheat straw pretreated for bioethanol production. Biotechnol. Biofuels 1, 1-9. https://doi.org/10.1186/1754-6834-1-5

Li, J., Henriksson, G., Gellerstedt, G., 2007. Lignin depolymerization/repolymerization and its critical 

https://doi.org/10.1016/j.biortech.2006.10.018

Li, X., Tabil, L.G., Panigrahi, S., 2007. Chemical treatments of natural fiber for use in natural fiberreinforced composites: A review. J. Polym. Environ. 15, 25-33. https://doi.org/10.1007/s10924006-0042-3

Liu, M., Thygesen, A., Summerscales, J., Meyer, A.S., 2017. Targeted pre-treatment of hemp bast fibres for optimal performance in biocomposite materials: A review. Ind. Crops Prod. 108, 660683. https://doi.org/10.1016/j.indcrop.2017.07.027

Mamiński, M., Trzepałka, A., Auriga, R., H’Ng, P.S., Chin, K.L., 2018. Physical and mechanical properties of thin high density fiberboard bonded with 1,3-dimethylol-4,5dihydroxyethyleneurea (DMDHEU). J. Adhes. 96, 679-690. https://doi.org/10.1080/00218464.2018.1500280

Manshor, M.R., Anuar, H., Nur Aimi, M.N., Ahmad Fitrie, M.I., Wan Nazri, W.B., Sapuan, S.M., ElShekeil, Y.A., Wahit, M.U., 2014. Mechanical, thermal and morphological properties of durian skin fibre reinforced PLA biocomposites. Mater. Des. 59, 279-286. https://doi.org/10.1016/j.matdes.2014.02.062

Mati-Baouche, N., De Baynast, H., Lebert, A., Sun, S., Lopez-Mingo, C.J.S., Leclaire, P., Michaud, P., 2014. Mechanical, thermal and acoustical characterizations of an insulating bio-based composite made from sunflower stalks particles and chitosan. Ind. Crops Prod. 58, 244-250. https://doi.org/10.1016/j.indcrop.2014.04.022

Melo, R.R., Stangerlin, D.M., Santana, R.R.C., Pedrosa, T.D., 2014. Physical and mechanical properties of particleboard manufactured from wood, bamboo and rice husk. Mater. Res. 17, 682-686. https://doi.org/10.1590/S1516-14392014005000052

Merk, S., Blume, A., Riederer, M., 1997. Phase behaviour and crystallinity of plant cuticular waxes studied by Fourier transform infrared spectroscopy. Planta 204, 44-53. https://doi.org/10.1007/s004250050228

Mishra, S., Naik, J.B., Patil, Y.P., 2000. The compatibilising effect of maleic anhydride on swelling and mechanical properties of plant-fiber-reinforced novolac composites. Compos. Sci. Technol. 60, 1729-1735. https://doi.org/10.1016/S0266-3538(00)00056-7

Mishra, S., Sain, M., 2009. Commercialization of wheat straw as reinforcing filler for commodity thermoplastics. J. Nat. Fibers 6, 83-97. https://doi.org/10.1080/15440470802703851 
Mosier, N.S., Hendrickson, R., Brewer, M., Ho, N., Sedlak, M., Dreshel, R., Welch, G., Dien, B.S., Aden, A., Ladisch, M.R., 2005. Industrial scale-up of $\mathrm{pH}$-controlled liquid hot water pretreatment of corn fiber for fuel ethanol production. Appl. Biochem. Biotechnol. - Part A Enzym. Eng. Biotechnol. 125, 77-97. https://doi.org/10.1385/ABAB:125:2:077

Mwaikambo, L.Y., Ansell, M.P., 2002. Chemical modification of hemp, sisal, jute, and kapok fibers by alkalization. J. Appl. Polym. Sci. 84, 2222-2234. https://doi.org/10.1002/app.10460

Oushabi, A., 2019. The pull-out behavior of chemically treated lignocellulosic fibers/polymeric matrix interface (LF/PM): A review. Compos. Part B Eng. 174. https://doi.org/10.1016/j.compositesb.2019.107059

Putra, A.E.E., Renreng, I., Arsyad, H., Bakri, B., 2020. Investigating the effects of liquid-plasma treatment on tensile strength of coir fibers and interfacial fiber-matrix adhesion of composites. Compos. Part B Eng. 183. https://doi.org/10.1016/j.compositesb.2019.107722

Qin, L., Qiu, J., Liu, M., Ding, S., Shao, L., Lü, S., Zhang, G., Zhao, Y., Fu, X., 2011. Mechanical and thermal properties of poly(lactic acid) composites with rice straw fiber modified by poly(butyl acrylate). Chem. Eng. J. 166, 772-778. https://doi.org/10.1016/j.cej.2010.11.039

Rakesh Kumar1, Sangeeta Obrai1, A.S., 2011. Chemical modifications of natural fiber for composite material. Der Chem. Sin. 4, 219-228.

Saari, N., Hashim, R., Sulaiman, O., Hiziroglu, S., Sato, M., Sugimoto, T., 2014. Properties of steam treated binderless particleboard made from oil palm trunks. Compos. Part B Eng. 56, 344-349. https://doi.org/10.1016/j.compositesb.2013.08.062

Sahai, R.S.N., Pardeshi, R.A., 2019. Comparative study of effect of different coupling agent on mechanical properties and water absorption on wheat straw-reinforced polystyrene composites. J. Thermoplast. Compos. Mater. 1-18. https://doi.org/10.1177/0892705719843975

Santos, E.B.C., Moreno, C.G., Barros, J.J.P., de Moura, D.A., de Carvalho Fim, F., Ries, A., Wellen, R.M.R., Da Silva, L.B., 2018. Effect of alkaline and hot water treatments on the structure and morphology of piassava fibers. Mater. Res. 21, 1-11. https://doi.org/10.1590/1980-5373-MR2017-0365

Scaffaro, R., Maio, A., Gulino, E.F., Megna, B., 2019. Structure-property relationship of PLA-Opuntia Ficus Indica biocomposites. Compos. Part B Eng. 167, 199-206. https://doi.org/10.1016/j.compositesb.2018.12.025 
Scaffaro, R., Maio, A., Gulino, E.F., Pitarresi, G., 2020. Lignocellulosic fillers and graphene nanoplatelets as hybrid reinforcement for polylactic acid: Effect on mechanical properties and degradability. Compos. Sci. Technol. 190, 108008. https://doi.org/10.1016/j.compscitech.2020.108008

Scaffaro, R., Maio, A., Lopresti, F., 2018. Physical properties of green composites based on poly-lactic acid or Mater-Bi ${ }^{\circledast}$ filled with Posidonia Oceanica leaves. Compos. Part A Appl. Sci. Manuf. 112, 315-327. https://doi.org/10.1016/j.compositesa.2018.06.024

Segal, L., Creely, J.J., Martin, A.E., Conrad, C.M., 1959. An Empirical Method for Estimating the Degree of Crystallinity of Native Cellulose Using the X-Ray Diffractometer. Text. Res. J. 29, 786794. https://doi.org/10.1177/004051755902901003

Shi, S.Q., Gardner, D.J., 2001. Dynamic adhesive wettability of wood. Wood Fiber Sci. 33, 58-68.

Sun, R.C., Salisbury, D., Tomkinson, J., 2003. Chemical composition of lipophilic extractives released during the hot water treatment of wheat straw. Bioresour. Technol. 88, 95-101. https://doi.org/10.1016/S0960-8524(02)00290-0

Tarrés, Q., Vilaseca, F., Herrera-Franco, P.J., Espinach, F.X., Delgado-Aguilar, M., Mutjé, P., 2019. Interface and micromechanical characterization of tensile strength of bio-based composites from polypropylene and henequen strands. Ind. Crops Prod. 132, 319-326. https://doi.org/10.1016/j.indcrop.2019.02.010

Tian, S.Q., Zhao, R.Y., Chen, Z.C., 2018. Review of the pretreatment and bioconversion of lignocellulosic biomass from wheat straw materials. Renew. Sustain. Energy Rev. 91, 483-489. https://doi.org/10.1016/j.rser.2018.03.113

Tran, T.P.T., Bénézet, J.C., Bergeret, A., 2014. Rice and Einkorn wheat husks reinforced poly(lactic acid) (PLA) biocomposites: Effects of alkaline and silane surface treatments of husks. Ind. Crops Prod. 58, 111-124. https://doi.org/10.1016/j.indcrop.2014.04.012

Tribot, A., Delattre, C., Badel, E., Dussap, C.G., Michaud, P., de Baynast, H., 2018. Design of experiments for bio-based composites with lignosulfonates matrix and corn cob fibers. Ind. Crops Prod. 123, 539-545. https://doi.org/10.1016/j.indcrop.2018.07.019

Wang, F., Zhou, S., Yang, M., Chen, Z., Ran, S., 2018. Thermo-mechanical performance of polylactide composites reinforced with Alkali-treated bamboo fibers. Polymers (Basel). 10. https://doi.org/10.3390/polym10040401

Wu, H., Dai, X., Zhou, S.L., Gan, Y.Y., Xiong, Z.Y., Qin, Y.H., Ma, J., Yang, L., Wu, Z.K., Wang, T.L., 
Wang, W.G., Wang, C.W., 2017. Ultrasound-assisted alkaline pretreatment for enhancing the enzymatic hydrolysis of rice straw by using the heat energy dissipated from ultrasonication. Bioresour. Technol. 241, 70-74. https://doi.org/10.1016/j.biortech.2017.05.090

Xiao, L.-P., Lin, Z., Peng, W.-X., Yuan, T.-Q., Xu, F., Li, N.-C., Tao, Q.-S., Xiang, H., Sun, R.-C., 2014. Unraveling the structural characteristics of lignin in hydrothermal pretreated fibers and manufactured binderless boards from Eucalyptus grandis. Sustain. Chem. Process. 2, 9. https://doi.org/10.1186/2043-7129-2-9

Yang, Y., Shen, H., Qiu, J., 2020. Bio-inspired self-bonding nanofibrillated cellulose composite: A response surface methodology for optimization of processing variables in binderless biomass materials produced from wheat-straw-lignocelluloses. Ind. Crops Prod. 149, 112335. https://doi.org/10.1016/j.indcrop.2020.112335

Yu, Z., Xiao, Y., Tian, H., Liu, S., Zeng, J., Luo, X., 2019. Bagasse as functional fillers to improve and control biodegradability of soy oil-based rigid polyurethane foams. Korean J. Chem. Eng. 36, 1740-1745. https://doi.org/10.1007/s11814-019-0349-0

Zandi, A., Zanganeh, A., Hemmati, F., Mohammadi-Roshandeh, J., 2019. Thermal and biodegradation properties of poly(lactic acid)/rice straw composites: effects of modified pulping products. Iran. Polym. J. (English Ed. 28, 403-415. https://doi.org/10.1007/s13726-019-00709-3

Zheng, Q., Zhou, T., Wang, Y., Cao, X., Wu, S., Zhao, M., Wang, H., Xu, M., Zheng, B., Zheng, J., Guan, X., 2018. Pretreatment of wheat straw leads to structural changes and improved enzymatic hydrolysis. Sci. Rep. 8, 1-9. https://doi.org/10.1038/s41598-018-19517-5

Zhu, L., Qiu, J., Liu, W., Sakai, E., 2019. Mechanical and thermal properties of rice Straw / PLA modi fi ed by nano Attapulgite / PLA interfacial layer. Compos. Commun. 13, 18-21. https://doi.org/10.1016/j.coco.2019.02.001 